\title{
Ionic liquid-based liquid-phase microextraction, a new sample enrichment procedure for liquid chromatography
}

\author{
Jing-fu Liu ${ }^{\text {a }}$, Yu-guang Chi ${ }^{\text {a,b }}$, Gui-bin Jiang ${ }^{\text {a,* }}$, Chao Tai ${ }^{\text {a }}$, Jin-feng Peng ${ }^{\text {a }}$, Jing-Tian Hu ${ }^{\text {b }}$ \\ ${ }^{a}$ Key Laboratory of Environmental Chemistry and Ecotoxicology, Research Center for Eco-Environmental Sciences, \\ Chinese Academy of Sciences, P.O. Box 2871, Beijing 100085, China \\ ${ }^{\mathrm{b}}$ Department of Chemistry, Shandong University, Jinan 250100, China
}

Received 10 July 2003; received in revised form 4 November 2003; accepted 5 November 2003

\begin{abstract}
Room temperature ionic liquids (RTILs) were used as extraction solvent in liquid-phase microextraction (LPME) coupled with liquid chromatography. Using 1-hexyl-3-methylimidazolium hexafluorophosphate $\left(\left[\mathrm{C}_{6} \mathrm{MIM}\right]\left[\mathrm{PF}_{6}\right]\right)$ as extraction solvent, some parameters related to LPME of 4-nonylphenol (4-NP) and 4-tert-octylphenol (4-t-OP) were optimized. Although $\left[\mathrm{C}_{6} \mathrm{MIM}^{-\mathrm{P}}\left[\mathrm{PF}_{6}\right]\right.$ can suspend a much larger volume of drop on the needle of the microsyringe than the conventional solvents such as 1-octanol and carbon tetrachloride, the method sensitivity was analyte dependent because of the different partition coefficients and the relatively large viscosity of $\left[\mathrm{C}_{6} \mathrm{MIM}\left[\mathrm{PF}_{6}\right]\right.$. The proposed procedure has a detection limit and enrichment factor of $0.3 \mu \mathrm{g} 1^{-1}$ and 163 for $4-\mathrm{NP}$, and $0.7 \mu \mathrm{g} 1^{-1}$ and 130 for $4-t$-OP, respectively. Aqueous samples including tap water, river water, and effluent from sewage treatment plant were analyzed by the proposed method and the recoveries at $10 \mu \mathrm{g} \mathrm{l}^{-1}$ spiked level were in the range of $90-113 \%$.
\end{abstract}

(c) 2003 Elsevier B.V. All rights reserved.

Keywords: Ionic liquids; Liquid-phase microextraction; Extraction methods; Nonylphenol; Octylphenol; Alkylphenols

\section{Introduction}

Liquid-phase microextraction (LPME), performed by using a single drop of solvent [1-4] or a small length of porous hollow fiber-protected solvent [5], has shown to be an attractive alternative for sample preparation. It was reported that LPME has comparable extraction efficiency and reproducibility with the widely used solid-phase microextraction. The advantage of LPME is that it is inexpensive and there is freedom of selection of appropriate solvent for extraction of definite analytes. However, drop-based LPME suffered from the relatively small drop volume (typically $1 \mu \mathrm{l}$ ) and thus low sensitivity in high-performance liquid chromatography (HPLC). Furthermore, the commonly used solvents in LPME are incompatible with reversed-phase HPLC.

Room temperature ionic liquids (RTILs) are ionic media resulting from combination of organic cations and various anions that are liquids at room temperature. 1-Hexyl-3methylimidazolium hexafluorophosphate $\left(\left[\mathrm{C}_{6} \mathrm{MIM}\right]\left[\mathrm{PF}_{6}\right]\right)$,

\footnotetext{
* Corresponding author. Fax: +86-1062923563.

E-mail address: gbjiang@mail.rcees.ac.cn (G.-b. Jiang).
}

one of the typical RTILs, was reported to have large viscosity, low miscibility with water and moderate dissolvability of organic compounds [6-9]. Therefore, it should be possible to suspend a large volume drop on the needle of a microsyringe for efficient LPME and thereby provide high sensitivity for HPLC determination. In our previous study, $\left[\mathrm{C}_{8} \mathrm{MIM}\right]\left[\mathrm{PF}_{6}\right]$ was used to LPME of polycyclic aromatic hydrocarbons with higher enrichment factor than that with traditional solvents [10].

The 4-nonylphenol (4-NP) and 4-tert-octylphenol (4-tOP), two major alkylphenols in aquatic environment, are mainly come from the degradation production of 4-nonylphenol polyethoxylates and 4-tert-octylphenol polyethoxylates [11], which are two groups of non-ionic surfactants widely used as detergents, wetting agents, emulsifiers and stabilizers [12]. Being more persistent than their parent compounds and have been found to elicit estrogenic activities [13], 4-NP and 4-t-OP have received a great deal of attention in recent years, and various analytical methods over these contaminants has emerged recently [14].

The objective of this study is to exploit the potentiality of RTILs for LPME of 4-NP and 4-t-OP. Some LPME 
related parameters were optimized and the proposed procedure was applied to determine 4-NP and 4-t-OP in aqueous samples.

\section{Experimental}

\subsection{Reagents and samples}

4-NP and 4-t-OP were obtained from Tokyo Kasei Kogyo, Japan. Standard stock solutions $\left(1000 \mu \mathrm{g} \mathrm{ml}^{-1}\right)$ of these compounds were prepared in methanol. Working solutions were prepared daily by appropriate dilution of the stock solutions with water. Reagents for synthesis of RTILs including 1-methylimidazole (99\%), 1-chlorohexane $(95 \%)$ and hexafluorophosphoric acid (60 wt.\% solution in water) were obtained from Acros Organics. HPLC-grade methanol and acetonitrile was purchased from Scharlace (Barcelona, Spain). All the other chemicals were analytical grade reagents (Beijing Chemicals, Beijing, China) and ultrapure water (EASYpure LF) water was used throughout.

Tap water sample was collected from water tap in our laboratory, river water samples were collected from the Haihe River in Tianjin, and the wastewater sample was the effluent collected at Gaobeidian sewage treatment plant in the east part of Beijing city. Collected samples were filtered through a cellulose membrane with pore size $0.45 \mu \mathrm{m}$ and maintained in glass containers, then stored at a temperature of $4{ }^{\circ} \mathrm{C}$.

\subsection{RTIL synthesis}

1-Hexyl-3-methylimidazolium hexafluorophosphate $\left(\left[\mathrm{C}_{6}\right.\right.$ $\mathrm{MIM}]\left[\mathrm{PF}_{6}\right]$ ) was synthesized as described elsewhere $[8,9,15]$. Briefly, [ $\left.\mathrm{C}_{6} \mathrm{MIM}\right] \mathrm{Cl}$ was prepared by adding equal amounts $(0.2 \mathrm{~mol})$ of 1-methylimidazole and 1-chlorohexane to a round-bottomed flask fitted with a reflux condenser and reacting for $48 \mathrm{~h}$ at $70^{\circ} \mathrm{C}$. The above produced $\left[\mathrm{C}_{6} \mathrm{MIM}\right] \mathrm{Cl}$ was washed with ether and dried under vacuum at $80^{\circ} \mathrm{C}$. $\left[\mathrm{C}_{6} \mathrm{MIM}\right]\left[\mathrm{PF}_{6}\right]$ was prepared by slowly adding hexafluorophosphoric acid $(0.13 \mathrm{~mol})$ to $\left[\mathrm{C}_{6} \mathrm{MIM}\right] \mathrm{Cl}(0.1 \mathrm{~mol})$ in $100 \mathrm{ml}$ of water. After stirring for $12 \mathrm{~h}$, the lower liquid portion was washed with water until the washings were no longer acidic. The RTILs were cleaned up with $\mathrm{Al}_{2} \mathrm{O}_{3}$ and dried under vacuum at $80^{\circ} \mathrm{C}$.

\subsection{Extraction procedure}

Withdrew $10 \mu \mathrm{l}$ of $\left[\mathrm{C}_{6} \mathrm{MIM}\right]\left[\mathrm{PF}_{6}\right]$ into a $50-\mu 1$ microsyringe (Agilent), clamped the microsyringe into place such that the needle of the syringe was immersed into the $15 \mathrm{ml}$ sample solution held in a vial, then depressed the plunger to expose a $10 \mu l$ of $\left[\mathrm{C}_{6} \mathrm{MIM}\right]\left[\mathrm{PF}_{6}\right]$ drop to the sample and turn on the magnetic stirrer. After stirring for the prescribed time, the $\left[\mathrm{C}_{6} \mathrm{MIM}\right]\left[\mathrm{PF}_{6}\right]$ drop was retracted into the microsyringe and then injected into the HPLC system for analysis. To sus-

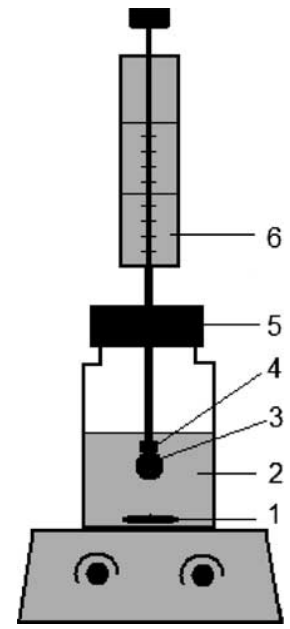

Fig. 1. Schematic diagram of the ionic liquid-based liquid-phase microextraction. (1) Stir bar; (2) sample solution; (3) RTIL drop; (4) PTFE tube; (5) septum; (6) microsyringe.

pend a $10-\mu 1\left[\mathrm{C}_{6} \mathrm{MIM}\right]\left[\mathrm{PF}_{6}\right]$ drop, the tip of the microsyringe needle was sheathed with a $3 \mathrm{~mm}$ long polytetrafluoroethylene (PTFE) tube with $(0.6 \mathrm{~mm}$ i.d. and $1.8 \mathrm{~mm}$ o.d.) as shown in Fig. 1. When carbon tetrachloride and 1-octanol were compared as extraction solvents, the same extraction procedure was performed but $\left[\mathrm{C}_{6} \mathrm{MIM}\right]\left[\mathrm{PF}_{6}\right]$ was replaced with the target solvent.

\subsection{HPLC determination}

The HPLC equipment included an Agilent 1100 Series IsoPump, an Agilent 1100 Series FLD fluorescence detector set at $220 \mathrm{~nm}$ excitation and $315 \mathrm{~nm}$ emission, and a personal computer equipped with an Agilent ChemStation program for LC used to process chromatographic data. A 7725 injector (Rheodyne, USA) and an Agilent Zorbax RX-C 18 column $(150 \mathrm{~mm} \times 4.6 \mathrm{~mm}$, particle size $5 \mu \mathrm{m})$ were used for injection and separation of the analytes enriched in the RTILs. The mobile phase was a mixture of acetonitrile-water $(70: 30(v / v))$.

\section{Results and discussion}

\subsection{Comparison of extraction solvent}

The physical and chemical properties such as density, viscosity and solubility of extraction solvents have significant influence on the extraction efficiency of target analytes. Therefore, three solvents including $\left[\mathrm{C}_{6} \mathrm{MIM}\right]\left[\mathrm{PF}_{6}\right]$, carbon tetrachloride and 1-octanol, with physicochemical parameters shown in Table 1, were compared as extraction solvents in this study.

Experiments demonstrated that the largest drop that could stably suspended on the tip of the microsyringe needle (sheathed with a $0.6 \mathrm{~mm}$ i.d., $1.8 \mathrm{~mm}$ o.d. and $3 \mathrm{~mm}$ long 
Table 1

Some physicochemical properties of the studied solvents and analytes

\begin{tabular}{|c|c|c|c|c|c|}
\hline & {$\left[\mathrm{C}_{6} \mathrm{MIM}\right]\left[\mathrm{PF}_{6}\right]$} & Carbon tetrachloride & 1-Octanol & 4-NP & $4-t-\mathrm{OP}$ \\
\hline Molecular mass & 312 & 153 & 130 & 220 & 206 \\
\hline Melting point $\left({ }^{\circ} \mathrm{C}\right)$ & & $-23^{\mathrm{a}}$ & $-16^{\mathrm{a}}$ & $81-83^{\mathrm{b}}$ & \\
\hline Density $\left(\mathrm{g} \mathrm{ml}^{-1}\right)$ & $1.29^{\mathrm{c}}$ & $1.59^{\mathrm{a}}$ & $0.83^{\mathrm{a}}$ & $0.953^{\mathrm{b}}$ & $0.922^{b}$ \\
\hline Viscosity $\left(25^{\circ} \mathrm{C}, \mathrm{Pa}\right)$ & $0.586^{\mathrm{c}}$ & $9.6 \times 10^{-4 a}$ & $9.0 \times 10^{-3 a}$ & & \\
\hline Solubility in water $\left(\mathrm{mgl}^{-1}\right)$ & $7500^{d}$ & $8000^{\mathrm{a}}$ & $300^{\mathrm{a}}$ & $5.4^{\mathrm{b}}$ & $12.6^{\mathrm{b}}$ \\
\hline $\log K_{\text {ow }}$ & & & & $4.48^{\mathrm{b}}, 4.2^{\mathrm{b}}$ & $4.12^{\mathrm{b}}$ \\
\hline
\end{tabular}

${ }^{a}$ Ref. [16].

${ }^{b}$ Ref. [17].

c Ref. [9].

${ }^{\mathrm{d}}$ Ref. [15].

polytetrafluoroethylene tube) was $10 \mu$ f for RTILs, and $5 \mu \mathrm{l}$ for 1-octanol and carbon tetrachloride, respectively. Therefore, a drop volume of $5 \mu \mathrm{l}$ was adopted for comparing the enrichment efficiency. Table 2 showed the obtained analytical signals (peak area) when $25 \mu \mathrm{gl}^{-1} 4-\mathrm{NP}$ and 4-t-OP were extracted for $20 \mathrm{~min}$ by using $\left[\mathrm{C}_{6} \mathrm{MIM}\right]\left[\mathrm{PF}_{6}\right]$, 1-octanol and carbon tetrachloride as extractant, respectively. Results shown in Table 2 indicate that 1-octanol possessed the largest peak area for both 4-NP and 4-t-OP. When $\left[\mathrm{C}_{6} \mathrm{MIM}\right]\left[\mathrm{PF}_{6}\right]$ was adopted, the peak area of $4-t-\mathrm{OP}$ was almost the same as that when 1-octanol was used; but the peak area of 4-NP was only half of that when 1-octanol was used. The partition coefficients $\left(\log K_{\text {ow }}\right)$ of 4-NP and 4-t-OP between 1-octanol and water were shown in Table 1. The partition coefficients of 4-NP and 4-t-OP between $\left[\mathrm{C}_{4} \mathrm{MIM}\right]\left[\mathrm{PF}_{6}\right]$ and water are not available, but can be expected to be one magnitude lower than that in a 1-octanol-water system as it was reported that the partition coefficients of organic compounds in $\left[\mathrm{C}_{4} \mathrm{MIM}\right]\left[\mathrm{PF}_{6}\right] /$ water system is generally one magnitude lower than that in 1-octanol-water [18]. The partition coefficients of the analytes between two phases is a very important parameter of extraction and higher partition coefficients is beneficial for getting enrichment factor [5]. Therefore, it seems reasonable that 1-octanol provided larger peak area. However, LPME is usually a non-equilibrium procedure, and the obtained peak area is the complex result of various parameters including partition coefficient and diffusion coefficient of analyte, solubility of extraction solvent, viscosity of both sample solution and solvent. Considering that the largest suspended drop volume of $\left[\mathrm{C}_{6} \mathrm{MIM}\right]\left[\mathrm{PF}_{6}\right]$ is two times of that of 1-octanol, it was expected that $\left[\mathrm{C}_{6} \mathrm{MIM}\right]\left[\mathrm{PF}_{6}\right]$ should

Table 2

The obtained peak area when $25 \mu \mathrm{g} \mathrm{l}^{-1} 4-\mathrm{NP}$ and $4-t$-OP were extracted for $20 \mathrm{~min}$ by using $5-\mu 1$ drop of different solvents

\begin{tabular}{lcl}
\hline & $4-\mathrm{NP}$ & $4-t-\mathrm{OP}$ \\
\hline$\left[\mathrm{C}_{6} \mathrm{MIM}\right]\left[\mathrm{PF}_{6}\right]$ & 76 & 215 \\
$1-$ Octanol & 164 & 222 \\
Carbon tetrachloride & 76 & 165 \\
\hline
\end{tabular}

provide the largest peak area for both 4-NP and 4-t-OP if the largest drop was adopted. Thus, further comparison of extraction solvents was conducted.

\subsection{Drop volume and extraction time}

Fig. 2 showed the effect of $\left[\mathrm{C}_{6} \mathrm{MIM}\right]\left[\mathrm{PF}_{6}\right]$ drop volume and extraction time on the HPLC peak area, which was studied by exposing a 5 or $10-\mu l$ drop to aqueous sample solution for different time. For further comparison with 1-octanol, a 5- $\mu$ l 1-octanol drop was also exposed to aqueous sample solution for different time with results shown in Fig. 2. As can be seen, when a $5-\mu 1\left[\mathrm{C}_{6} \mathrm{MIM}\right]\left[\mathrm{PF}_{6}\right]$ drop was adopted, the peak area increased with the increasing of extraction time up to $20 \mathrm{~min}$, then decreased gradually with the increasing of extraction time due to the dissolution of $\left[\mathrm{C}_{6} \mathrm{MIM}\right]\left[\mathrm{PF}_{6}\right]$ in sample solution. If a $10-\mu 1\left[\mathrm{C}_{6} \mathrm{MIM}\right]\left[\mathrm{PF}_{6}\right]$ drop was adopted, however, the peak area increased with extraction time within $40 \mathrm{~min}$, and the obtained peak area was almost three-fold that when 5- $\mu \mathrm{l}$ drop was adopted. From Fig. 2, it is clear that the obtained peak area of 4-NP by using a 5- $\mu$ l drop of 1-octanol was much larger than that by using $5 \mu l\left[\mathrm{C}_{6} \mathrm{MIM}\right]\left[\mathrm{PF}_{6}\right]$, which probably due to the higher partition coefficient of 4-NP in the 1-octanol-water system and the much lower viscosity of 1-octanol. For 4-t-OP, however, the obtained peak area by using $5 \mu l 1$-octanol was almost the same as that by using $5 \mu 1\left[\mathrm{C}_{6} \mathrm{MIM}\right]\left[\mathrm{PF}_{6}\right]$ when the extraction time was less than $20 \mathrm{~min}$, but larger than with $5 \mu 1\left[\mathrm{C}_{6} \mathrm{MIM}\right]\left[\mathrm{PF}_{6}\right]$ over $20 \mathrm{~min}$ due to the dissolution of $\left[\mathrm{C}_{6} \mathrm{MIM}\right]\left[\mathrm{PF}_{6}\right]$ in sample solution. In conclusion, $10 \mu \mathrm{l}$ $\left[\mathrm{C}_{6} \mathrm{MIM}\right]\left[\mathrm{PF}_{6}\right]$ provided the largest peak area of $4-t-\mathrm{OP}$ while $5 \mu$ l 1-octanol possessed the largest peak area of 4-NP. A drop of $10 \mu l\left[\mathrm{C}_{6} \mathrm{MIM}\right]\left[\mathrm{PF}_{6}\right]$ and an extraction time of $40 \mathrm{~min}$ were adopted in the following study.

\subsection{Sample volume}

The influence of sample volume on the peak area was studied in the range of 5-25 ml. Results indicated that with the increasing of sample volume, the peak area of $4-t$-OP decreased significantly wile the peak area of 4-NP decreased very slowly. We suspected that the decrease of peak area 


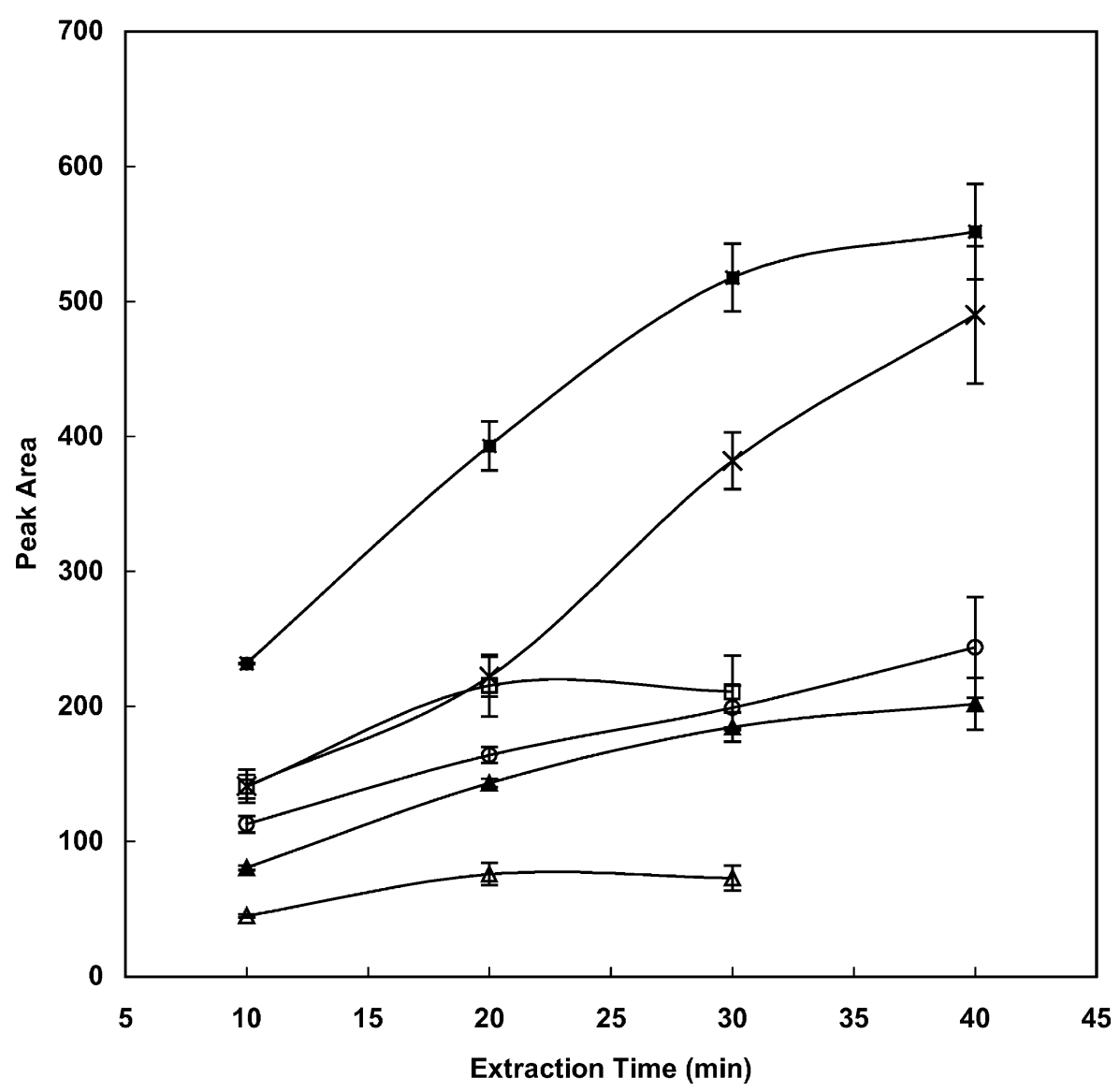

Fig. 2. The effect of drop volume and time on extraction of $15 \mathrm{ml}$ of $25 \mu \mathrm{g} 1^{-1}$ spiked 4-NP and 4-t-OP. ( $\square$ ) 4-t-OP, $5 \mu 1$ [C $\left.4 \mathrm{MIM}_{4} \mathrm{PF}_{6}\right] ;(\triangle)$ 4-NP, $5 \mu \mathrm{l}$

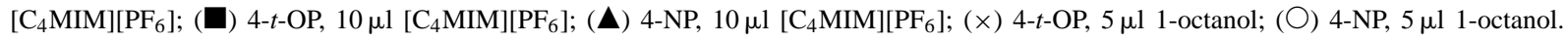

was due to the fact that more amount of $\left[\mathrm{C}_{6} \mathrm{MIM}\right]\left[\mathrm{PF}_{6}\right]$ was dissolved into the sample solution, and thus less residual RTILs drop could be injected into the HPLC system for detection. To demonstrate this assumption, the sample solution was saturated with $\left[\mathrm{C}_{6} \mathrm{MIM}\right]\left[\mathrm{PF}_{6}\right]$ before extraction to eliminate the dissolution of $\left[\mathrm{C}_{6} \mathrm{MIM}\right]\left[\mathrm{PF}_{6}\right]$ drop for extraction. It was found that the peak area increased gradually with the sample volume in the range of $5-25 \mathrm{ml}$. This result demonstrated that our assumption is right. A sample volume of $15 \mathrm{ml}$ was adopted in the following studies as lower sample volume resulted in inconvenient operation for extraction.

\subsection{Analytical performance}

Under the above selected conditions, some characters of the proposed method were investigated. The enrichment factor and precisions (R.S.D., $n=5$ ) of the proposed procedure, measured by repeated enrichment of standard solution containing $25 \mu \mathrm{g} 1^{-1} 4-\mathrm{NP}$ and 4-t-OP, were 163 and $7.8 \%$ for $4-\mathrm{NP}$, and 130 and $3.2 \%$ for $4-t$-OP, respectively. The enrichment factor is defined as the ratio of $C_{\mathrm{o}} / C_{\mathrm{a}}$, where $C_{\mathrm{o}}$ is the concentration of analytes in the RTILs phase after extraction and $C_{\mathrm{a}}$ is the original concentration of analytes in the aqueous phase. The correlation coefficients $\left(R^{2}\right)$ obtained by determining six 4-NP and 4-t-OP standards covering the linear range of $10-100 \mu \mathrm{g} \mathrm{I}^{-1}$ were 0.9995 and 0.9992 , and the detection limits $(\mathrm{S} / \mathrm{N}=3)$ were $0.3 \mu \mathrm{g}^{-1}$ for $4-\mathrm{NP}$ and $0.7 \mu \mathrm{g}^{-1}$ for $4-t$-OP, respectively.

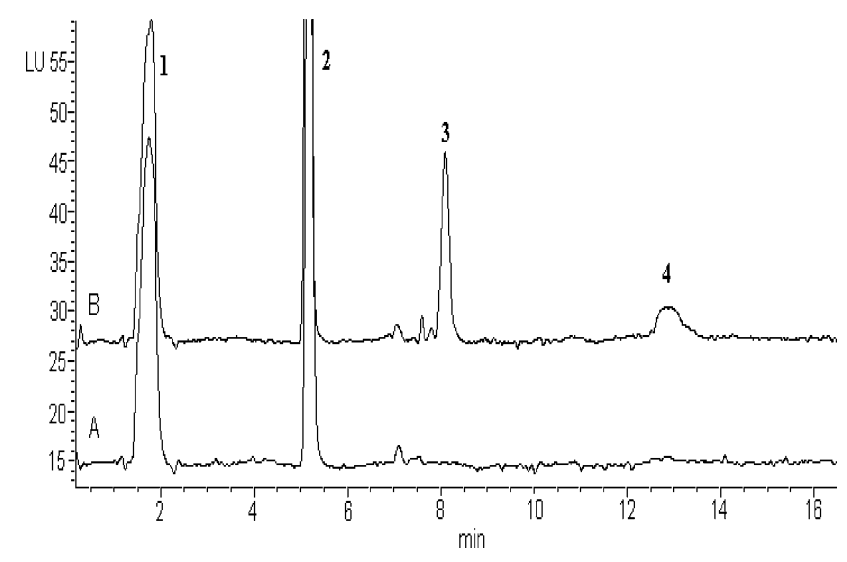

Fig. 3. Typical chromatograms of effluent collected from a local sewage treatment plant. (A) Sample blank; (B) sample spiked with $10 \mu \mathrm{gl} \mathrm{l}^{-1}$ 4- $t$-OP and 4-NP. Peaks identified as: (1) $\left[\mathrm{C}_{6} \mathrm{MIM}\right]\left[\mathrm{PF}_{6}\right]$; (2) unknown substance; (3) 4-t-OP; (4) 4-NP. 


\subsection{Application of the method for aqueous samples}

In order to validate the proposed method, three aqueous samples including tap water, river water, and effluent from sewage treatment plant were analyzed and the recoveries were determined at $10 \mu \mathrm{g} 1^{-1} 4-\mathrm{NP}$ and 4-t-OP spiked level. Results indicate that the contents of 4-NP and 4-t-OP in the samples were under the detection limits. The recoveries of 4-NP and 4-t-OP were in the range of 91-113, and $90-111 \%$, respectively. Fig. 3 showed the typical chromatograms of effluent collected from a local sewage treatment plant.

\section{Conclusions}

A novel technique, RTILs-based LPME, was proposed for the enrichment of analytes in environmental aqueous samples. Compared with the conventional solvents such as 1-octanol and carbon tetrachloride, $\left[\mathrm{C}_{6} \mathrm{MIM}\right]\left[\mathrm{PF}_{6}\right]$ can suspend a much larger volume of drop on the needle of the syringe, but the method sensitivity was analyte dependent because of its different partition coefficient and the relatively large viscosity of $\left[\mathrm{C}_{6} \mathrm{MIM}\right]\left[\mathrm{PF}_{6}\right]$. Compared with 1-octanol, $\left[\mathrm{C}_{6} \mathrm{MIM}\right]\left[\mathrm{PF}_{6}\right]$ provided higher sensitivity for $4-t-\mathrm{OP}$ but lower sensitivity for 4-NP. Furthermore, RTILs are compatible with reversed-phase HPLC. The proposed RTILs-based LPME procedure is an inexpensive and one-step microextraction technique that can conveniently coupled with HPLC.

\section{Acknowledgements}

This work was jointly supported by the National Natural Science Foundation of China (20377045), the National Key Project for Basic Research (2002CB412308), and the State High Tech Development Plan (2002AA641010).

\section{References}

[1] S. Liu, P.K. Dasgupta, Anal. Chem. 67 (1995) 2042.

[2] M.A. Jeannot, F.F. Cantwell, Anal. Chem. 68 (1996) 2236

[3] Y. He, H.K. Lee, Anal. Chem. 69 (1997) 4634.

[4] A.L. Theis, A.J. Waldadack, S.M. Hansen, M.A. Jannot, Anal. Chem. 73 (2001) 5651.

[5] G. Shen, H.K. Lee, Anal. Chem. 74 (2002) 648.

[6] J.G. Huddleston, H.D. Willauer, R.P. Swatloski, A.E. Visser, R.D. Rogers, Chem. Commun. (1998) 1765.

[7] D.W. Armstrong, L. He, Y.-S. Liu, Anal. Chem. 71 (1999) 3873.

[8] S. Carda-Broch, A. Berthod, D.W. Armstrong, Anal. Bioanal. Chem. 375 (2003) 191.

[9] J.G. Huddleston, A.E. Visser, W.M. Reichert, H.D. Willauer, G.A Broker, R.D. Rogers, Green Chem. 3 (2001) 156.

[10] J.-F. Liu, G.-B. Jiang, Y.-G. Chi, Y.-Q. Cai, Q.-X. Zhou, J.-T. Hu, Anal. Chem. 23 (2003) 5870.

[11] M. Ahel, W. Giger, M. Koch, Water Res. 28 (1994) 1131.

[12] T.A. Aboul-Kassim, B.R.T. Simoneit, Critic. Rev. Environ. Sci. Technol. 23 (1993) 325.

[13] S. Jobling, D. Shesahan, J.A. Osborne, P. Matthiessen, J.P. Sumpter, Environ. Toxicol. Chem. 15 (1996) 194.

[14] H. Lee, Water Qual. Res. J. Can. 34 (1999) 3.

[15] S. Chun, S.V. Dzyuba, R.A. Bartsch, Anal. Chem. 73 (2001) 3737.

[16] Merck database, hettp://chemdat.merk.de/.

[17] R.J. Maguire, Water Qual. Res. J. Can. 34 (1999) 37.

[18] J.G. Huddleston, H.D. Willauer, R.P. Swatloski, A.E. Visser, R.D. Rogers, Chem. Commun. (1998) 1765. 